\title{
AFP mRNA level in enriched circulating tumor cells from hepatocellular carcinoma patient blood samples is a pivotal predictive marker for metastasis
}

Junhua $\mathrm{Jin}^{1} *$, Xiaojuan $\mathrm{Niu}^{2}$, Lihui $\mathrm{Zou}^{1} *$, Lin $\mathrm{Li}^{3} *$, Shugang $\mathrm{Li}^{4}$, Jingli Han ${ }^{1}$, Peiying Zhang ${ }^{4}$, Jinghai Song ${ }^{2 \dagger}$, Fei Xiao $^{1 \dagger}$

${ }^{1}$ The Key Laboratory of Geriatrics, Beijing Institute of Geriatrics, ${ }^{2}$ Department of Surgery,

${ }^{3}$ Department of Oncology, Beijing Hospital. ${ }^{4}$ Xuzhou Central Hospital, Affiliated Hospital of Medical College of Southeast University, P. R. China.

*These authors contributed equally to this work.

† Corresponding author. Tel: +861058115046; Fax: +861065237929

E-mail address: xiaofei@bjhmoh.cn (F. Xiao), jhaisong2003@163.com (J. Song)

Nonstandard abbreviations: CTCs, Circulating Tumor Cells; HCC, Hepatocellular Carcinoma; AFP, Alpha Fetoprotein; HepG2, Hepatocellular carcinoma cell lines; EpCAM, Epithelial Cell Adhesion Molecule. 


\section{Abstract}

Circulating tumor cells quantification may be helpful for evaluating cancer dissemination, predicting prognosis and assessing therapeutic effectiveness and safety. In present study, CTCs from blood samples of 72 patients with hepatocellular carcinoma (HCC) were enriched with anti-EpCAM nanoparticles. AFP mRNA level was detected by nested PCR after enrichment of CTCs from HCC blood samples at 0 , 3, 6, 9 and 12 months after hepatectomy, respectively. AFP mRNA expression in CTCs was positive in 43 patients (59.7\%) and negative in 29 patients (40.3\%) before hepatectomy. 10 and 11 were diagnosed as intrahepatic/extrahepatic metastasis before and after hepatectomy, respectively, among 43 patients with positive AFP mRNA expression in CTCs before hepatectomy. And these 21 patients with metastasis have maintained AFP mRNA of CTCs positive during the whole tested year. Specifically, 3 patients with AFP mRNA negative in CTCs before hepatectomy changed to be positive at 6 and 9 months, and 2 of them were diagnosed as metastasis at 12 months after hepatectomy. We conclude that the positive AFP mRNA of CTCs can be a pivotal predictor for HCC metastasis before and after hepatectomy. The release of AFP expression from hepatocellular carcinoma cells into circulation must be a major source of HCC metastasis.

\section{Introduction}




\subsection{Circulating tumor cells}

Circulating tumor cells (CTCs) are traveling cells in physiological fluids released from a primary or metastatic tumor. CTCs quantification may be helpful for evaluating cancer dissemination, predicting prognosis and assessing therapeutic effectiveness and safety. During tumor management, one of the important tasks is to predict the metastatic ability of a primary tumor. Detachment of cancer cells from primary tumors is an initial step in the metastatic process. Furthermore, it can be used in subsequent proteomic and functional genetic analyses [1-3]. Isolation of CTCs from peripheral blood may facilitate early diagnosis and timely treatment. As CTCs are extraordinarily rare in the background of millions of normal hematopoietic cells (approximately $1 \mathrm{CTC}$ in the background of millions of normal hematopoietic cells), their identification and characterization require extremely sensitive and specific analytical methods, which are usually a combination of enrichment and detection procedures, posing a great technological challenge to our current knowledge. In fact, liquid biopsy, a method of isolating CTCs from peripheral blood, is expected to complement conventional tissue biopsies in the detection of metastatic tumors. During the detection of CTCs, the specific proteins overexpressed on the surface of their plasma membrane are often determined, and these proteins are often used as targets in CTCs sensing methodologies for different types of cancer cells.

\subsection{Epithelial cell adhesion molecule}


Epithelial cell adhesion molecule (EpCAM), a type I glycosylated membrane protein with a molecular weight of $30-40 \mathrm{kDa}$, has been found to be involved in tumor invasion and metastasis [4-6]. EpCAM is abundant in most epithelial tissues but absent in blood cells and functions as a hemophilic $\mathrm{Ca}^{2+}$-independent cell-cell adhesion molecule. Furthermore, EpCAM is considered a general marker for a large variety of epithelial cells, thus EpCAM could be applied as a proper target to separate CTCs from the blood. However, many molecular analyses on CTCs demonstrate that CTCs and normal epithelial cells share the same molecule of EpCAM. Method of detecting CTCs by EpCAM is not always specific, which means further verification should be applied to characterize the CTCs captured by EpCAM antibody.

Currently, a novel method that has been very well established for immuno-isolation of CTCs from blood is to conjugate antibodies against EpCAM to magnetic beads, followed by purification of captured cells through a magnetic field, which has been used to enrich CTCs from the blood of patients with breast, prostate, and colon cancers [7-9].

\subsection{Alpha-fetoprotein}

Alpha-fetoprotein (AFP) is a glycoprotein comprising of 591 amino acids with a half-life of 5-7 days. Normally, AFP is produced by fetal yolk sac, liver and intestine. Elevated AFP protein level is often used as a serological marker for HCC $[10,11]$ as 
studies have demonstrated that AFP is overexpressed in liver carcinoma cells $[12,13]$ and strongly correlated with the invasiveness of cancer cells. AFP monitoring in HCC patients has been recommended in many academic organizations including the European Association for the Study of the Liver [14], the Asian Pacific Association for the Study of the Liver[15]. Notably, increase of serum AFP protein level is not only present in HCC patients but also in patients with chronic hepatitis or cirrhosis [16].

Although many studies have elucidated that AFP mRNA in the peripheral blood might be a predictor for HCC recurrence after liver transplantation [17], this technique remains controversial. Furthermore, some research mentions that a larger volume of blood is required (15-20 ml) [17-20]. However, the value of AFP mRNA level in CTCs in predicting HCC recurrence or metastasis before or after hepatectomy has not been well elucidated. In some studies, the positive rates of AFP mRNA were $20 \%-50 \%$ before hepatic resection and transplantation [19-22]. This variability can be attributed to the differences in laboratory techniques, primer selections, intervals between sample collection and processing, and various populations.

In current study, we have established a method to monitor the AFP expression using nested PCR technology in CTCs enriched by EpCAM antibody coated on the surface of magnetic beads. We try to provide a simple and rapid way to isolate and identify the circulating tumor cells from blood samples. In addition, we attempt to assess the value of AFP mRNA expression of CTCs enriched by anti-EpCAM nanoparticles in predicting $\mathrm{HCC}$ recurrence or metastasis before and after 
hepatectomy.

\section{Materials and methods}

\subsection{Information of HCC patients}

Ethics approval was obtained from the Ethics Committee of Beijing Hospital. All the patients enrolled in this study signed the informed consents. The diagnosis of HCC was confirmed histologically. Peripheral blood samples from 72 HCC patients were collected in citrated sodium anticoagulant tubes after hepatectomy at $0,3,6,9$ and 12 months, respectively. There were 10 patients diagnosed as metastasis before surgical resection. The number of male $(n=46)$ was larger than female $(\mathrm{n}=26)$ in HCC patients. Most HCC patients were infected with HBV $(\mathrm{n}=48)$ and some of them were infected with $\mathrm{HCV}(\mathrm{n}=10) .9$ patients were dead within 12 months. These results were consistent with other studies about HCC in China [23,24]. The information of patients was browsed in Table 1. Peripheral blood samples were collected from 20 healthy subjects as negative controls.

\subsection{Cell culture}

Human hepatoblastoma cell line HepG2 was obtained from the Concord Cell Center (Peking Union Medical College, Beijing, China) and applied as a positive control in this protocol. Cells were cultured in Eagle minimum essential medium (MEM, Invitrogen) supplemented with $10 \%$ 
fetal bovine serum (Hyclone, American) and incubated in a humidified condition at a temperature of $37^{\circ} \mathrm{C}$ with $5 \% \mathrm{CO}_{2}$. The medium was replaced every 3 days. Cells were harvested when they were subconfluent. The total amount of cells was calculated by a hemocytometer.

\subsection{CTCs isolation by anti-EpCAM nanoparticles}

In our present experiment, CTCs were captured immediately by anti-EpCAM nanoparticles and AFP mRNA levels were detected at 0, 3, 6, 9 and 12 months, respectively. Cell lysis buffer (Blood isolation kit, Biochain) was applied to remove the red blood cells. Peripheral blood nucleated cells (PBNCs), including CTCs, were isolated from $3 \mathrm{ml}$ of blood samples (citrated sodium anticoagulant) from each patient. After being washed in phosphate-buffered saline (PBS) and centrifuged at $1500 \mathrm{rpm}$ for $5 \mathrm{~min}$, cell pellets were resuspended in $1 \mathrm{ml}$ of PBS and then 20 $\mu 1$ human anti-EpCAM nanoparticals (MagVigen, Nvigen) were added to incubate for $60 \mathrm{~min}$ at room temperature. After incubation, the nanoparticles (with binding cells) were separated from the solution by a magnet.

\subsection{RNA extraction and nested PCR}

Total RNA of CTCs enriched by anti-EpCAM nanoparticals was extracted by TRIzol (Invitrogen) based on the method of acid guanidinium thiocyanate-phenol-

chloroform extraction. Total RNA of each sample was denatured at $70^{\circ} \mathrm{C}$ for 3 min and annealed with $1 \mu \mathrm{g}$ of random primer at $37^{\circ} \mathrm{C}$ for $2 \mathrm{~min}$. Reverse transcriptase reaction was carried out in 
$1 \times$ reverse transcriptase buffer [50mM Tris- $\mathrm{HCl}(\mathrm{pH} 8.3), 75 \mathrm{mM} \mathrm{KCl}$, and $3 \mathrm{mM} \mathrm{MgCl} 2$ ] with $10 \mathrm{mM}$ DTT, $1 \mu \mathrm{l}$ of deoxynucleoside triphosphate (dNTP) mixture ( $250 \mathrm{mM}$ each dNTP), and 200 units of moloney murine leukemia virus reverse transcriptase (Superscript, Invitrogen), respectively. The cDNAs were synthesized in a total volume of $20 \mu \mathrm{l}$ at $42^{\circ} \mathrm{C}$ for $90 \mathrm{~min}$ and the reaction was stopped at $70^{\circ} \mathrm{C}$ for $10 \mathrm{~min}$.

In order to increase the sensitivity of this method, we designed nested PCR to amplify AFP mRNA. This step was conducted with gene-specific primers that lie within different exons to avoid nonspecific bindings and could generate outer and inner PCR products of $353 \mathrm{bp}$ and $198 \mathrm{bp}$, respectively. Sequences of AFP primers used in the experiment were as follows: the sense primers of the outer product was 5' CAA TTC TTC TTT GGG CTG CTC GCT ATG AC 3' (AFP 1) and the inner one was 5' ATG CAG TTG AAT GCT TCC AA 3' (AFP 3), the antisense primer of the outer product was 5' AGT GTC TTG TTG AGA ACA TAT GTA GGA CAT G 3' (AFP 2) and the inner one was 5' CCA CAT CCA GGA CTA GTT TCT 3' (AFP 4), respectively. Glyceraldehyde 3-phosphate dehydrogenase (GAPDH) was served as an internal control to ensure the same amount of total RNA being reverse-transcribed to cDNAs in each assay. For GAPDH RT-PCR amplification, the sense primer was 5' ACC ACA GTC CAT GCC ATC AC 3' and the antisense primer was 5‘ TCC ACC ACC CTG TTG CTG TA 3' (451 bp). PCR was performed in a total volume of $25 \mu \mathrm{l}$ with $1 \times$ PCR buffer [20 mM Tris- $\mathrm{HCl}(\mathrm{pH} 8.4), 50 \mathrm{mM} \mathrm{KCl}$, and $2.5 \mathrm{mM}$ $\mathrm{MgCl}_{2}$ ], $1 \mu \mathrm{l}$ of dNTPs mixture ( $250 \mathrm{mM}$ each dNTP), 10 pmol of sense and antisense primers, 2.5 units of Taq DNA polymerase, $18 \mu 1$ of cDNA for AFP outer PCR and $2 \mu 1$ for GAPDH PCR, respectively. The inner AFP PCR amplification was conducted by application of $1 \mu 1$ of outer AFP PCR products as templates. PCR conditions were as follows: denatured at $94^{\circ} \mathrm{Cfor} 5 \mathrm{~min}$, followed 
by 35 cycles of $94^{\circ} \mathrm{C}$ for $30 \mathrm{sec}, 6^{\circ} \mathrm{C}$ for $30 \mathrm{sec}$, and $72^{\circ} \mathrm{C}$ for $30 \mathrm{sec}$, and a final extension at $72^{\circ} \mathrm{C}$ for $10 \mathrm{~min}$. Then, $5 \mu 1$ PCR products was electrophoresed in $1.5 \%(\mathrm{wt} / \mathrm{vol})$ agarose gelstained with ethidium bromide and visualized under a UV light.

2.5 The sensitivity of CTCs isolation by anti-EpCAM nanoparticles

In order to test the sensitivity of CTCs enrichment by anti-EpCAM nanoparticles, different concentrations of HepG2 cells were mixed with normal blood samples, and the enrichment of HepG2 by anti-EpCAM nanoparticles was performed afterwards. Captured CTCs were determined from the mixture of HepG2 with different numbers $(0,50,500,5000,50000)$ in several $3 \mathrm{ml}$ of normal blood samples. Then, the RNA extraction and nested PCR were performed to evaluate the sensitivity of CTCs isolation by anti-EpCAM nanoparticles.

\section{Results}

\subsection{The sensitivity of AFP mRNA nested PCR to detect CTCs}

The sensitivity of this method is indicated in Fig.1. A positive band of AFP mRNA nested PCR products could be observed from the mixture of at least 50 HepG2 cells in $3 \mathrm{ml}$ of blood sample. This result suggested that the sensitivity of this test was high enough to detect CTCs from $3 \mathrm{ml}$ of blood sample. 


\subsection{Results of AFP mRNA nested PCR to detect CTCs}

Nested PCR showed that AFP mRNA in CTCs were positive in 43 patients (59.7\%) and negative in 29 patients (40.3\%) before hepatectomy (Table 1). Among them, 23 remained positive and 26 remained negative during the whole test stage (Fig.2).

Ten of 23 patients with persisting positive results after surgery had been diagnosed as metastasis by PET/CT before hepatectomy, indicating that positive AFP mRNA expression in CTCs might be a biomarker for metastasis in HCC patients. In order to observe the role of positive AFP mRNA in CTCs in HCC metastasis, we focused on the remaining 13 patients with persisting positive AFP mRNA expression in CTCs but without metastasis before surgery. We found that 5 of them were diagnosed as metastasis by PET/CT at 4, 5, and 6 months after hepatectomy, respectively. Another 6 patients received a second chemotherapy at 9 months after hepatectomy. Although it had not been confirmed by PET/CT so far, these 6 patients who had received a second chemotherapy could be considered as with metastasis. Thus, 21 of 23 patients with persisting positive results developed metastasis within the 12 post-operative months (Fig.2).

AFP mRNA in 20 of 43 patients with positive AFP mRNA in CTCs before surgery became negative in 3-6 months after hepatectomy (Fig.2). Furthermore, AFP mRNA in 9 of these 20 patients switched to positive again at the 9 th or 12 th months after hepatectomy, respectively. No metastasis was found among the remaining 11 
patients during the test stage.

Surprisingly, AFP mRNA of CTCs in 3 of 29 patients with negative results before surgery became positive at 6,9 , and 12 months and remained positive till the follow-up deadline. Moreover, 2 of these 3 patients were diagnosed as metastasis by PET/CT at the 9th and 12th months, respectively.

\subsection{Differentiation features of HCC patients by pathologic diagnosis}

The differentiation features by pathologic diagnosis of the AFP mRNA positive and negative patients before surgery are listed in Table 2. In 43 patients with positive AFP mRNA before surgery, their HCC were 16,18 and 3 poorly, moderately and highly differentiated by pathologic diagnosis, respectively. However, in 29 patients with negative AFP mRNA in CTCs before surgery, there were 2, 10 and 13 patients diagnosed as poorly, moderately and highly differentiated by pathologic diagnosis respectively. These results gave us a hint that most AFP mRNA positive might be poorly or moderately differentiated and most AFP mRNA negative might be highly differentiated by pathologic diagnosis. As we know, low differentiation is more likely to get metastasis. These results further inferred that positive AFP mRNA in CTCs could be applied as an early and valuable predictor for HCC metastasis.

\subsection{Serum AFP levels in HCC patients}


Currently, the correlation between serum AFP protein standards and HCC diagnosis remains controversy in many studies [17-19], since high serum AFP protein level can also exist in many patients with hepatitis or cirrhosis [16]. Usually, AFP protein in serum above $400 \mu \mathrm{g} / \mathrm{L}$ is widely used for HCC diagnosis in clinically setting [12-15]. Of these $72 \mathrm{HCC}$ patients, the serum AFP protein level was $3087.2 \pm$ $4046.1 \mu \mathrm{g} / \mathrm{L}$ which was far greater than $400 \mu \mathrm{g} / \mathrm{L}$, a widely accepted cutoff value for HCC diagnosis. However, the serum AFP protein level in 43 AFP mRNA-positive patients $(6197.2 \pm 3750.3 \mu \mathrm{g} / \mathrm{L})$ was significantly higher than that in 29 AFP mRNA-negative patients $(710.3 \pm 1338.5 \mu \mathrm{g} / \mathrm{L})$ before surgery (Fig.3).

In order to investigate the relationship between AFP protein and AFP mRNA expression in CTCs in HCC patients, we observed the changes of serum AFP protein and mRNA levels in different groups for 12 months after hepatectomy (Fig.4).

Patients were divided into 5 groups. The first group included 21 patients with metastasis in whom the AFP mRNA expression in CTCs remained positive throughout the following 12 months. The average of serum AFP protein level in this group decreased from $8561.0 \mu \mathrm{g} / \mathrm{L}$ before surgery to $128.0 \mu \mathrm{g} / \mathrm{L}$ at 3 months after hepatectomy, then prominently increased to $700.3 \mu \mathrm{g} / \mathrm{L}$ at 6 months, and continuously increased to a higher level of $2209.5 \mu \mathrm{g} / \mathrm{L}$ at 9 months and dropped to $531.7 \mu \mathrm{g} / \mathrm{L}$ $(>400 \mu \mathrm{g} / \mathrm{L})$ at 12 months after surgery.

The second group consisted of 2 patients with persisting positive AFP mRNA expression in CTCs throughout the 12-month follow-up but without metastasis. The average serum AFP level in these 2 patients decreased from $7319.5 \mu \mathrm{g} / \mathrm{L}$ before 
surgery to $37.8 \mu \mathrm{g} / \mathrm{L}$ at 3-9 months after surgery, but it increased dramaticallyto752.0 $\mu \mathrm{g} / \mathrm{L}$ at 12 months after surgery.

The third group was comprised of 20 patients without metastasis but presenting positive AFP mRNA expression in CTCs before hepatectomy and developing to negative after hepatectomy, 9 of them became AFP mRNA-positive again at 12 months. The average of serum AFP level in these 20 patients decreased drastically from $3248.2 \mu \mathrm{g} / \mathrm{L}$ before surgery to $32.3 \mu \mathrm{g} / \mathrm{L}$ after surgery and maintained at a low standard during 12 months after hepatectomy.

The fourth group contained 3 patients with negative AFP mRNA expression in CTCs negative before hepatectomy but with positive results from the 6th to 12th months after hepatectomy. In addition, metastasis was detected in 2 of them at the 12th postoperative month. The average serum AFP in these 3 patients dropped from $4608.3 \mu \mathrm{g} / \mathrm{L}$ before surgery to $58.3 \mu \mathrm{g} / \mathrm{L}$ after surgery at 3-9 months, and it gradually increased to $438 \mu \mathrm{g} / \mathrm{L}$ at 12 months after surgery.

The fifth group consisted of 26 patients without metastasis exhibiting negative AFP mRNA expression in CTCs throughout the 12 postoperative months. The average of serum AFP level decreased from $402.1 \mu \mathrm{g} / \mathrm{L}$ before surgery to $16.3 \mu \mathrm{g} / \mathrm{L}$ after surgery, maintaining at a low level during the following 12 months after hepatectomy.

\section{Discussion}

HCC is one of the most fatal neoplasms worldwide. Because of its insidious 
pathogenesis, few clinical manifestations are seen in the early stages. Tragically, millions of people die from it after surgery without early detection and timely treatment due to the lack of efficient trace markers. Early detection of recurrence/metastasis is critical for surgical resection and long-term survival assessment. Meanwhile, tumor response to various therapeutic strategies should also be closely monitored.

CTCs need to be monitored because the occurrence of CTCs is the first step of tumor metastasis and it is a favorable biological marker for predicting prognosis [19,22-24]. Cancer cells may express EpCAM on their surface of cell membrane, EpCAM may be employed to isolate CTCs in the circulation. However, a few studies have demonstrated that CTCs detection has certain limitations, mainly because CTCs share the same molecule of EpCAM with normal epithelial cells. Therefore, methods for detecting CTCs by recognizing EpCAM are not sensitive enough. Thus, this method requires further improvement.

However, the amount of CTCs in the plasma is too small to be detected, especially when CTCs are mixed with millions of normal hematopoietic cells. Therefore, the identification, enrichment and characterization of CTCs in the plasma require an extremely sensitive and specific analytical method. In addition, AFP gene can be transcripted in HCC cells which can be released into circulation. Thus, the detection of AFP mRNA seems to be an alternative way to monitor tumor metastasis.

In our present study, we chose anti-EpCAM nanoparticles to enrich CTCs from serum, meanwhile, AFP nested RT-PCR was performed to detect AFP mRNA levels 
in blood samples from HCC patients before hepatectomy. Limited by its sensitivity threshold, this method can only detect 50 HepG2-positive cells mixed with $3 \mathrm{ml}$ of normal blood. Thus, this strategy is highly sensitive and specific for detecting CTCs in a small volume of blood samples. With this sensitive CTCs enrichment protocol by anti-EpCAM nanoparticles, AFP mRNA expression in CTCs is detected by nested RT-PCR from72 HCC patients. AFP mRNA was positive in 43 patients (59.7\%) and negative in 29 patients (40.3\%) before hepactectomy, respectively. In addition, it has been found that the positive rate of AFP mRNA was $20 \%-50 \%$ before hepatic resection and transplantation [19-22]. This variability can be attributed to differences in laboratory techniques, primer selection, interval between sample collection and processing, and participant populations. Pre-operative presence of AFP mRNA in CTCs may represent tumor cell detachment from primary HCC, also, there may be occult micro-metastasis that is undetectable pre-operatively.

In our current study, metastasis was detected in 21 of 23 patients with positive AFP mRNA in CTCs before hepatectomy and during the 12 postoperative months (Fig.2), suggesting that the positive AFP mRNA expression in CTCs may be a valuable predictor for HCC metastasis before and after hepatectomy. If the observation time was long enough, patients whose AFP mRNA expression reversed positive might progress to metastasis. Moreover, AFP mRNA of CTCs in 3 of 29 patients with negative results before surgery became positive at 6,9 , and 12 months and remained positive till the follow-up deadline. Furthermore, 2 of these 3 patients were diagnosed as metastasis by PET/CT at the 9th and 12th months, respectively. 
This data indicated that once the patients became AFP mRNA positive, the risk of metastasis was increased even though it was negative in the past. Thus AFP mRNA expression in CTCs can be an excellent predictor for metastasis of $\mathrm{HCC}$ after surgical resection.

We also noted that AFP mRNA levels did not correlate directly with serum AFP levels in HCC patients. However, the average of serum AFP levels was significantly higher in AFP mRNA-positive groups than in AFP mRNA-negative groups. Although the relationship between serum AFP protein levels and HCC diagnosis remains controversial in many studies [17-19], a serum AFP protein cutoff level of $\geq 400 \mu \mathrm{g} / \mathrm{L}$ is still a biomarker for HCC diagnosis [12-15]. However, serum AFP protein can also be very high in many other diseases, such as hepatitis and liver cirrhosis. Normally, AFP mRNA in CTCs appears prior to AFP protein in the circulation because it takes time for AFP mRNA to be translated into AFP protein. Thus, detection of AFP mRNA in CTCs seems to be superior to serum AFP protein.

In conclusion, our research demonstrates that hepatoma cells expressing AFP released into circulation may be a source of HCC metastasis. Detection of AFP mRNA levels in blood samples combined with anti-EpCAM nanoparticles and nested RT-PCR is a sensitive and specific method for predicting the recurrence and metastasis of $\mathrm{HCC}$, which provides new opportunities for early detection, prognosis prediction and therapeutic treatments for hepatocyte carcinoma.

\section{Acknowledgements}


This study was supported by grant from Grant 81571384 (to F. X.) from the

National Science Foundation of China, and Grant 2012AA02A511 (to F. X.) from the national the National High Technology Research and Development Program.

\section{Conflict of interest}

The authors declare no conflict of interest in the work presented.

\section{References}

[1]M. Yu, S. Stott, M. Toner, S. Maheswaran, D.A. Haber, Circulating tumor cells: approaches to isolation and characterization. The Journal of cell biology 192 (2011) 373-382.

[2]K. Pantel, C. Alix-Panabieres, Detection methods of circulating tumor cells. Journal of thoracic disease 4 (2012) 446-447.

[3]K. Pantel, C. Alix-Panabieres, The potential of circulating tumor cells as a liquid biopsy to guide therapy in prostate cancer. Cancer discovery 2 (2012) 974-975.

[4]S.V. Litvinov, M.P. Velders, H.A. Bakker, G.J. Fleuren, S.O. Warnaar, Ep-CAM: a human epithelial antigen is a homophilic cell-cell adhesion molecule. The Journal of cell biology 125 (1994) 437-446.

[5]W.J. Allard, J. Matera, M.C. Miller, M. Repollet, M.C. Connelly, C. Rao, A.G. Tibbe, J.W. Uhr, L.W. Terstappen, Tumor cells circulate in the peripheral blood of all major carcinomas but not in healthy subjects or patients with nonmalignant diseases. Clinical cancer research : an official journal of the American Association for Cancer Research 10 (2004) 6897-6904.

[6]S. Riethdorf, H. Fritsche, V. Muller, T. Rau, C. Schindlbeck, B. Rack, W. Janni, C. Coith, K. Beck, F. Janicke, S. Jackson, T. Gornet, M. Cristofanilli, K. Pantel, Detection of circulating tumor cells in peripheral blood of patients with metastatic breast cancer: a validation study of the cell search system. Clinical cancer research : an official journal of the American Association for Cancer Research 13 (2007) 920-928.

[7]S. Nagrath, L.V. Sequist, S. Maheswaran, D.W. Bell, D. Irimia, L. Ulkus, M.R. Smith, E.L. Kwak, S. Digumarthy, A. Muzikansky, P. Ryan, U.J. Balis, R.G. Tompkins, D.A. Haber, M. Toner, Isolation of rare circulating tumour cells in cancer patients by microchip technology. Nature 450 (2007) 1235-1239.

[8]D.F. Hayes, T.M. Walker, B. Singh, E.S. Vitetta, J.W. Uhr, S. Gross, C. Rao, G.V. Doyle, L.W. Terstappen, Monitoring expression of HER-2 on circulating epithelial cells in patients with 
advanced breast cancer. International journal of oncology 21 (2002) 1111-1117.

[9]G. Attard, J.F. Swennenhuis, D. Olmos, A.H. Reid, E. Vickers, R. A'Hern, R. Levink, F. Coumans, J. Moreira, R. Riisnaes, N.B. Oommen, G. Hawche, C. Jameson, E. Thompson, R. Sipkema, C.P. Carden, C. Parker, D. Dearnaley, S.B. Kaye, C.S. Cooper, A. Molina, M.E. Cox, L.W. Terstappen, J.S. de Bono, Characterization of ERG, AR and PTEN gene status in circulating tumor cells from patients with castration-resistant prostate cancer. Cancer research 69 (2009) 2912-2918.

[10]A.M. Di Bisceglie, J.H. Hoofnagle, Elevations in serum alpha-fetoprotein levels in patients with chronic hepatitis B. Cancer 64 (1989) 2117-2120.

[11]H. Oka, A. Tamori, T. Kuroki, K. Kobayashi, S. Yamamoto, Prospective study of alpha-fetoprotein in cirrhotic patients monitored for development of hepatocellular carcinoma. Hepatology 19 (1994) 61-66.

[12]S.R. Vora, H. Zheng, Z.K. Stadler, C.S. Fuchs, A.X. Zhu, Serum alpha-fetoprotein response as a surrogate for clinical outcome in patients receiving systemic therapy for advanced hepatocellular carcinoma. The oncologist 14 (2009) 717-725.

[13]T. Yau, T.J. Yao, P. Chan, H. Wong, R. Pang, S.T. Fan, R.T. Poon, The significance of early alpha-fetoprotein level changes in predicting clinical and survival benefits in advanced hepatocellular carcinoma patients receiving sorafenib. The oncologist 16 (2011) 1270-1279.

[14]J. Bruix, M. Sherman, J.M. Llovet, M. Beaugrand, R. Lencioni, A.K. Burroughs, E. Christensen, L. Pagliaro, M. Colombo, J. Rodes, E.P.o.E.o. HCC, Clinical management of hepatocellular carcinoma. Conclusions of the Barcelona-2000 EASL conference. European Association for the Study of the Liver. Journal of hepatology 35 (2001) 421-430.

[15]M. Omata, L.A. Lesmana, R. Tateishi, P.J. Chen, S.M. Lin, H. Yoshida, M. Kudo, J.M. Lee, B.I. Choi, R.T. Poon, S. Shiina, A.L. Cheng, J.D. Jia, S. Obi, K.H. Han, W. Jafri, P. Chow, S.G. Lim, Y.K. Chawla, U. Budihusodo, R.A. Gani, C.R. Lesmana, T.A. Putranto, Y.F. Liaw, S.K. Sarin, Asian Pacific Association for the Study of the Liver consensus recommendations on hepatocellular carcinoma. Hepatology international 4 (2010) 439-474.

[16]K.Q. Hu, N.L. Kyulo, N. Lim, B. Elhazin, D.J. Hillebrand, T. Bock, Clinical significance of elevated alpha-fetoprotein (AFP) in patients with chronic hepatitis $\mathrm{C}$, but not hepatocellular carcinoma. The American journal of gastroenterology 99 (2004) 860-865.

[17]Y. Wang, Z. Shen, Z. Zhu, R. Han, M. Huai, Clinical values of AFP, GPC3 mRNA in peripheral blood for prediction of hepatocellular carcinoma recurrence following OLT: AFP, GPC3 mRNA for prediction of HCC. Hepatitis monthly 11 (2011) 195-199.

[18]S. Marubashi, K. Dono, H. Nagano, Y. Sugita, T. Asaoka, N. Hama, A. Miyamoto, Y. Takeda, K. Umeshita, M. Monden, Detection of AFP mRNA-expressing cells in the peripheral blood for prediction of $\mathrm{HCC}$ recurrence after living donor liver transplantation. Transplant international : official journal of the European Society for Organ Transplantation 20 (2007) 576-582.

[19]M. Ijichi, T. Takayama, M. Matsumura, Y. Shiratori, M. Omata, M. Makuuchi, alpha-Fetoprotein mRNA in the circulation as a predictor of postsurgical recurrence of hepatocellular carcinoma: a prospective study. Hepatology 35 (2002) 853-860.

[20]K.S. Jeng, I.S. Sheen, Y.C. Tsai, Circulating messenger RNA of alpha-fetoprotein: a possible risk factor of recurrence after resection of hepatocellular carcinoma. Archives of surgery 139 (2004) 1055-1060.

[21]Y. Liu, M.C. Wu, G.X. Qian, B.H. Zhang, Detection of circulating hepatocellular carcinoma cells 
in peripheral venous blood by reverse transcription-polymerase chain reaction. Hepatobiliary \& pancreatic diseases international : HBPD INT 1 (2002) 72-76.

[22]H. Schmilovitz-Weiss, S.M. Stemmer, E. Liberzon, S. Avigad, J. Sulkes, A. Belinki, A. Kazatsker, Z. Ben-Ari, Quantitation of alpha-fetoprotein messenger RNA for early detection of recurrent hepatocellular carcinoma: a prospective pilot study. Cancer detection and prevention 30 (2006) 204-209.

[23]S. Tang, Y. Yuan, Y. He, D. Pan, Y. Zhang, Y. Liu, Q. Liu, Z. Zhang, Z. Liu, Genetic polymorphism of interleukin-6 influences susceptibility to HBV-related hepatocellular carcinoma in a male Chinese Han population. Human immunology 75 (2014) 297-301.

[24]Y. Yang, L. Jin, Y.L. He, K. Wang, X.H. Ma, J. Wang, Z. Yan, Y.L. Feng, Y.Q. Li, T.Y. Chen, H.L. Liu, Y.R. Zhao, Hepatitis B virus infection in clustering of infection in families with unfavorable prognoses in northwest China. Journal of medical virology 85 (2013) 1893-1899. 


\section{FIGURE LEGENDS}

Fig.1 The sensitivity test of AFP nested RT-PCR of positive cells captured from different numbers of HepG2 $(0,50,500,5000,50000)$ mixed with normal blood samples by anti-EpCAM nanoparticles enriching protocol. $\mathrm{M}$ means a DNA molecular marker, -ve means negative control.

Fig.2 The numbers of different groups of HCC patients. $\mathbf{M}+\mathbf{P}$, means the numbers of patients with metastasis and positive AFP mRNA of CTCs; NM+P, means the numbers of patients without metastasis but with positive AFP mRNA of CTCs; N, means the numbers of patients with negative AFP mRNA of CTCs; D, means the numbers of dead patients.

Fig.3 The serum AFP protein levels ( $\mu \mathrm{g} / \mathrm{L})$ of HCC patients with positive (red dots) or negative (black dots) AFP mRNA of CTCs before hepatectomy.

Fig.4 The serum AFP levels $(\mu \mathrm{g} / \mathrm{L})$ of HCC patients with positive or negative AFP mRNA nested PCR of CTCs at 0, 3, 6, 9 and 12 months after hepatectomy, respectively. $\mathbf{M}+\mathbf{P}$, means patients with metastasis and remaining positive AFP mRNA of CTCs for 12 months; NM+P, means patients without metastasis and retaining positive AFP mRNA of CTCs for 12 months; $\mathbf{N M + N + P}$, means patients without metastasis but with positive AFP mRNA before hepatectomy who became 
negative AFP mRNA of CTCs after hepatectomy, then nearly half of them recovered to positive AFP mRNA of CTCs at the12th month; $\mathbf{M}+\mathbf{N}+\mathbf{P}$, means patients with negative AFP mRNA of CTCs before hepatectomy, but became positive from 6 to 12 months after hepatectomy, and 2 of them were diagnosed as metastasis at the 12 th month; $\mathbf{N}$, means patients without metastasis and maintaining negative AFP mRNA of CTCs during 12 months. 


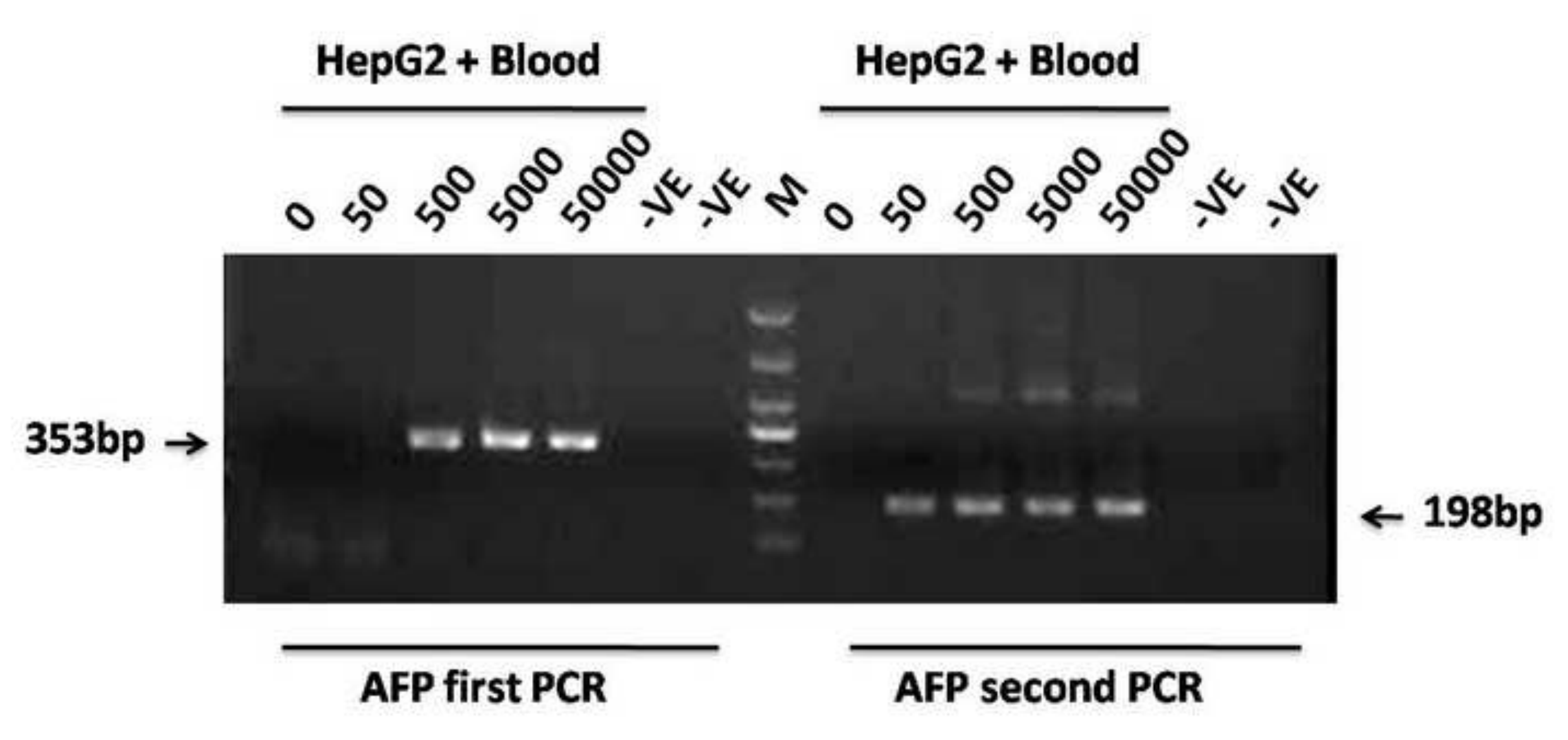

く. く $\cos 20$ AFP second PCR

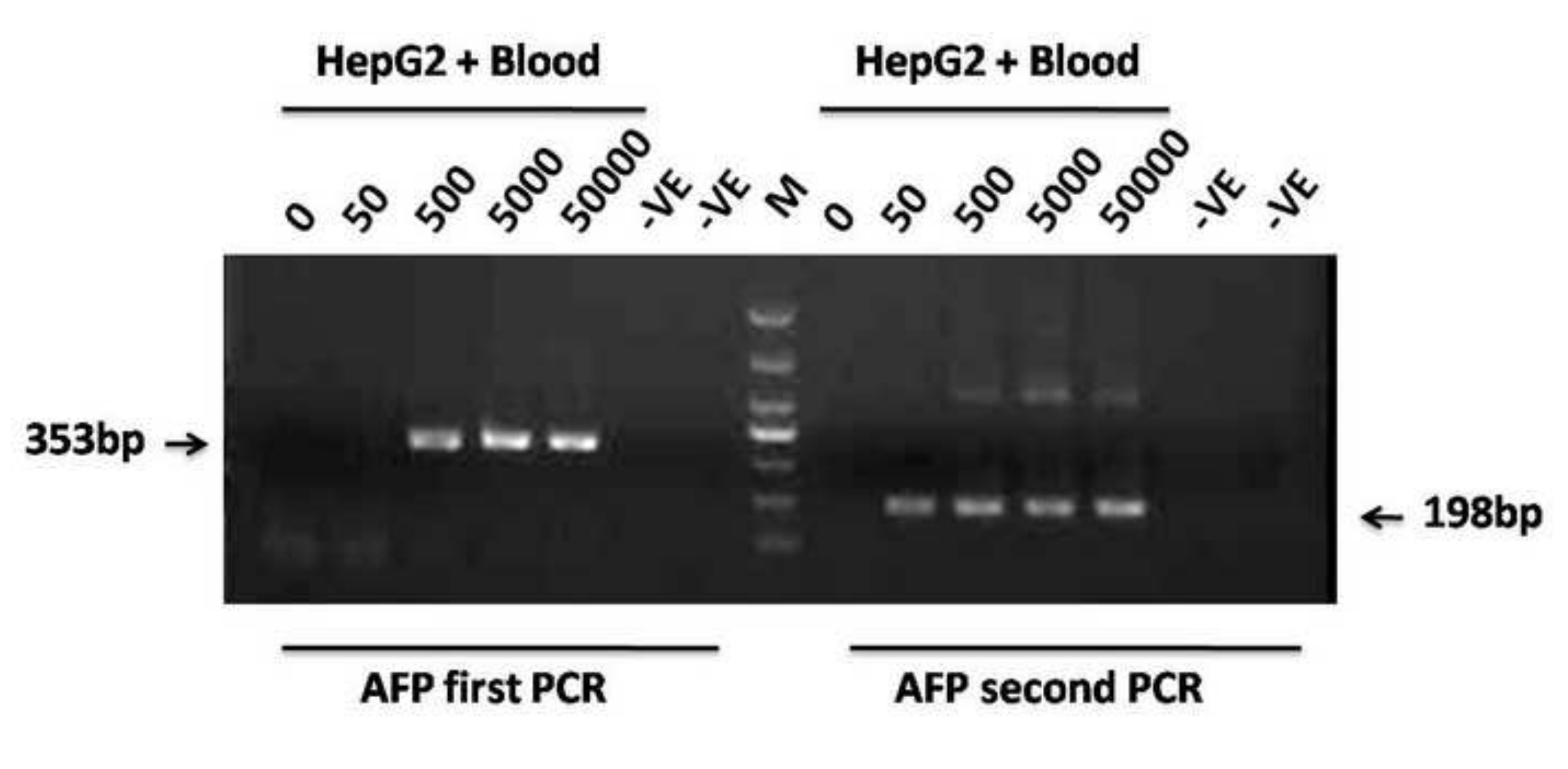

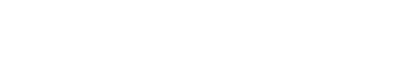
HepG2 + Blood HepG2 + Blood Blood




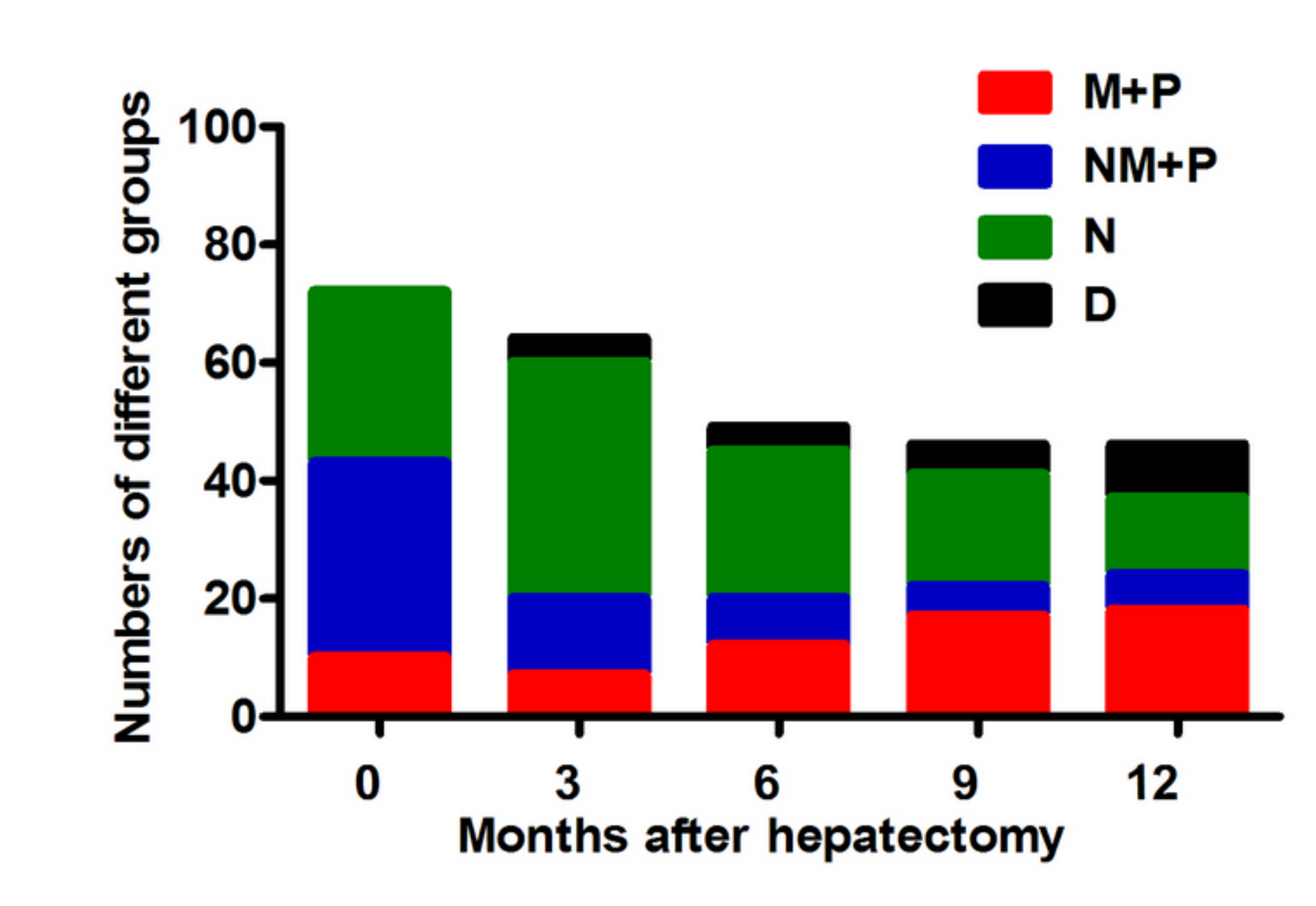

.

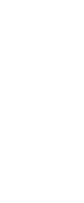

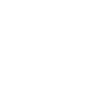

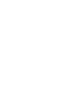

(

.

.




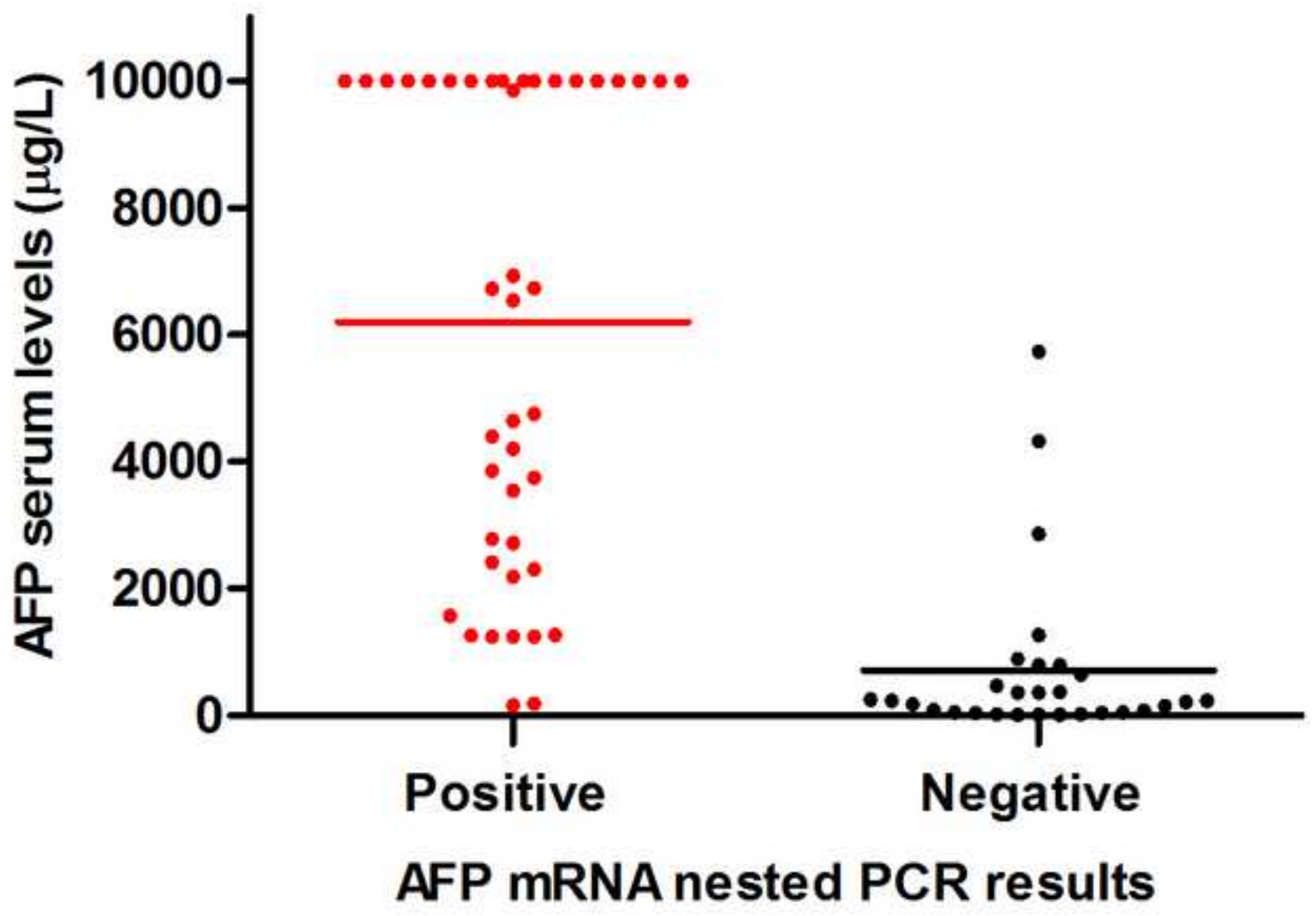




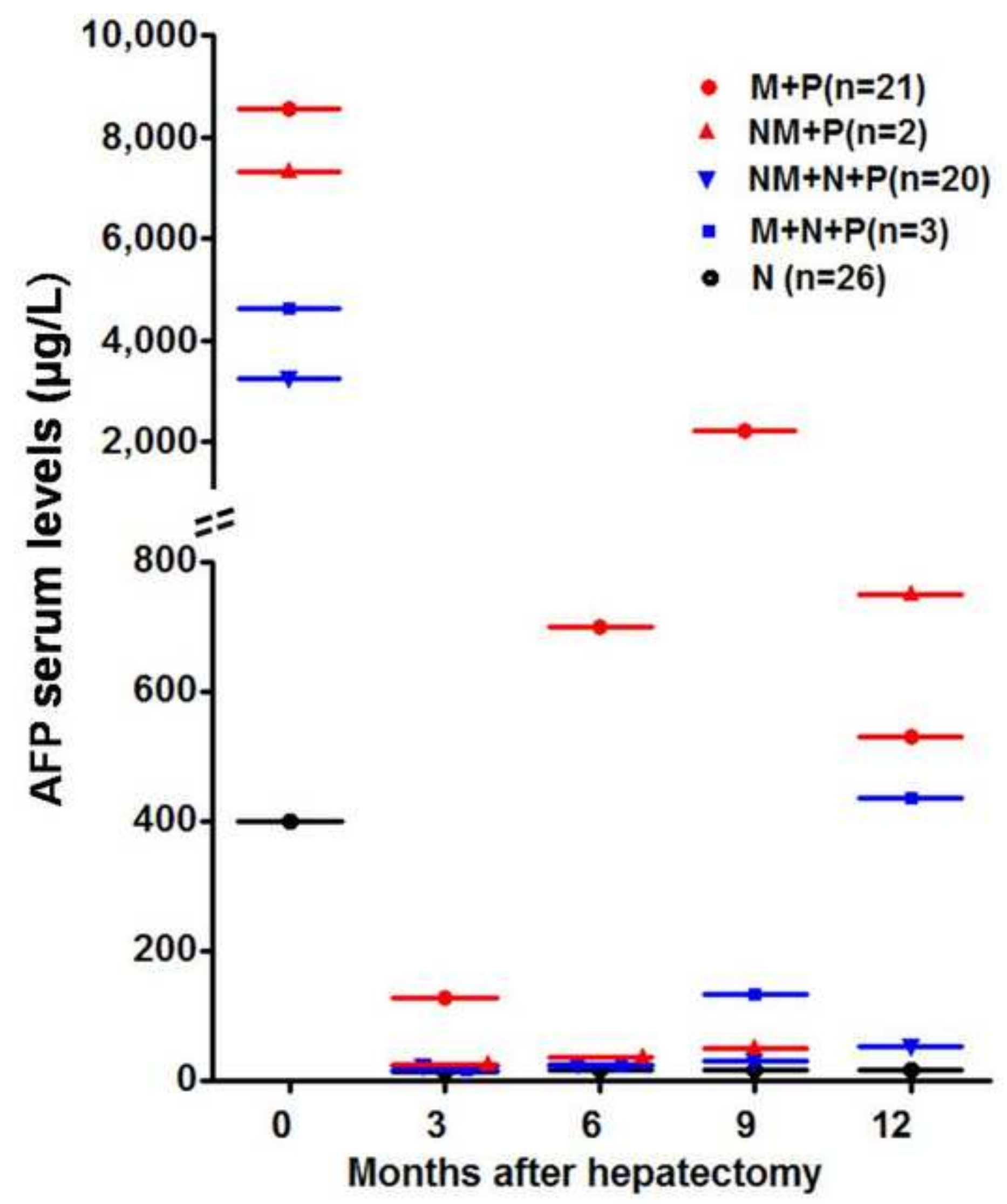

- $M+P(n=21)$

$N M+P(n=2)$

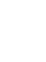

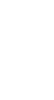

- $N M+N+P(n=20$

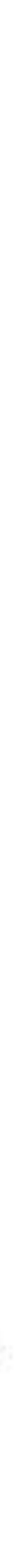


Table.1 Different features of HCC patients and AFP mRNA nested PCR results of CTCs captured from blood samples by anti-EpCAM nanoparticles protocol before hepatectomy.

\begin{tabular}{|c|c|c|c|c|}
\hline & Total No. & $\begin{array}{l}\text { AFP nested } \\
\text { Negative }\end{array}$ & $\begin{array}{c}\text { PCR results* } \\
\text { Positive }\end{array}$ & $\begin{array}{c}\text { Positive percent } \\
\text { (\%) }\end{array}$ \\
\hline $\mathrm{HCC}$ & 72 & 29 & 43 & 59.7 \\
\hline Female & 26 & 9 & 17 & 65.4 \\
\hline Male & 46 & 20 & 26 & 56.5 \\
\hline Metastasis & 10 & $\mathbf{0}$ & 10 & 100.0 \\
\hline Death & $\mathbf{9}^{\mathbf{a}}$ & 1 & 8 & 88.9 \\
\hline HBV & 48 & 17 & 31 & 64.6 \\
\hline HCV & 10 & 1 & 9 & 90.0 \\
\hline
\end{tabular}


Table.2 The differentiation features about positive and negative AFP mRNA of CTCs before surgery.

\begin{tabular}{cccc}
\hline $\begin{array}{c}\text { AFP } \\
\text { nested PCR }\end{array}$ & $\begin{array}{c}\text { Highly } \\
\text { differentiated }\end{array}$ & $\begin{array}{c}\text { Moderately } \\
\text { differentiated }\end{array}$ & $\begin{array}{c}\text { Poorly } \\
\text { differentiated }\end{array}$ \\
\hline positive & 3 & 18 & 16 \\
negative & 13 & 11 & 2 \\
\hline
\end{tabular}

